\title{
Has the HIV epidemic in rural Mwanza, Tanzania reached a plateau?
}

\author{
W. MWITA ${ }^{1 *}$, J. CHILONGANI ${ }^{1}$, R. WHITE ${ }^{2}$, G. MSHANA ${ }^{1}$, J. CHANGALUCHA ${ }^{1}$, \\ F.MOSHA ${ }^{1}$, D. ROSS ${ }^{2}$, B. ZABA ${ }^{1,2}$, and J. TODD ${ }^{3}$ \\ ${ }^{1}$ National Institute for Medical Research, P. O. Box 1462, Mwanza, Tanzania \\ ${ }^{2}$ The London School of Hygiene \& Tropical Medicine, London, U.K. \\ ${ }^{3}$ Medical Research Council Programme on AIDS in Uganda, Uganda Virus Research Institute, Entebbe, \\ Uganda
}

\begin{abstract}
Data from studies in Mwanza Region in Tanzania suggest stabilising HIV prevalence. The objective was to determine the factors that may have contributed to the relatively stable pattern of the HIV prevalence observed in the comparison communities of the Mwanza STD treatment trial in rural Mwanza Region, Tanzania between 1991 and 2001. Socio-demographic, sexual behaviour and HIV prevalence data in two surveys conducted 10 years apart in the same communities using similar sampling schemes were compared. The age standardised HIV prevalence was 3.8\% (95\% CI: 3.2-4.6) in 1991 and 4.3\% (95\% CI: 2.8-6.4) in 2001 for males ( $Z=-0.56$, $\mathrm{P}=0.58)$; and $4.5 \%(95 \% \mathrm{CI}: 3.8-5.3)$ in 1991 and 3.9\% (95\% CI: 2.6-5.6) in 2001 for females $(\mathrm{Z}=0.64, \mathrm{P}=$ 0.52). Participants in the 2001 survey reported significantly fewer lifetime and recent sexual partners (12 months), Sexually Transmitted disease syndromes (12 months) and significantly more condom use at last sex with casual partners than those in the 1991 behaviour survey. We conclude that STD/ HIV infection prevention activities in rural Mwanza may be responsible for changes in risky sexual behaviour and have successfully impeded the spread of HIV infection. These activities should therefore be enhanced to reduce HIV incidence even further. In addition, modelling studies are needed to assess whether mobility of HIV infected people out of rural communities may stabilise the prevalence of the HIV infection in the general populations.
\end{abstract}

Key words: HIV, prevalence, trend, sexual behaviour, population mobility, Tanzania

\section{Introduction}

It is estimated that, by the end of 2007, 33 million people worldwide were infected with the human immunodeficiency virus (HIV), $68 \%$ of whom live in sub-Saharan Africa (UNAIDS, 2007). The distribution of HIV in sub-Saharan Africa is uneven, some countries having an adult HIV prevalence as high as $25 \%$, while in other countries the prevalence is below $1 \%$ (UNAIDS, 2007). Within countries the aggregate HIV prevalence usually masks a large difference between rural and urban areas (WHO, 2000; Barongo et al., 1992).

The Joint United Nations Programme on HIV/ AIDS (UNAIDS) suggests that, in the natural course of HIV/AIDS epidemic, the relationship between prevalence and incidence varies as the epidemic ages. For instance, in an early stage of the epidemic, incidence and prevalence of HIV infection grows exponentially in the population at risk. As the epidemic grows and the number of people infected increases, the reproductive rate of infection is reduced which slows down the growth of incidence. Eventually, incidence declines while prevalence continues to grow. The prevalence of HIV decreases or levels off only when there is high migration of HIV positive people out of the communities or when mortality of those infected is greater or equal to incidence (UNAIDS, 1999). In an endemic steady state, prevalence of HIV infection is the product of incidence and the mean duration of infection (UNAIDS, 1999).

In Mwanza City in Tanzania, sentinel surveillance data among pregnant women, population based crosssectional and cohort studies among adults have shown a stable HIV prevalence of around 12\% from 1989 to 2000 (Barongo et al., 1990; Senkoro et al., 2000; MoH, 2005). Similar studies have shown that the prevalence of HIV in urban Bukoba in north-western Tanzania declined from $29 \%$ to $15 \%$ in women and from $17 \%$ to $10 \%$ in men from 1987 to 1996 (Kwesigabo et al., 1998; Kwesigabo, 2000; MoH, 2000). Studies within the Kisesa open cohort in rural Mwanza Region, Tanzania (20 km east of Mwanza City) have shown that the HIV prevalence among 15-44 year old adults increased from $5.9 \%(6.7 \%$ in females, $4.9 \%$ in males $)$ in 1994 to $6.6 \%(8.0 \%$ in females, $5.0 \%$ in males $)$ in 1996 with an incidence of $0.8 / 100$ person-years of observation (PYO). The HIV prevalence increased further to $8.1 \%$ (9.5\% in females, $6.7 \%$ in males) in 1999 with an incidence of 1.3/100PYO and remained

\footnotetext{
* Correspondence: Dr. Wambura Mwita; E-mail: wmwita@yahoo.com
} 
high in $2003,7.9 \%$ (8.2\% in females, $7.6 \%$ in males) with an incidence of 1.2/100PYO (Mwaluko et al., 2003; M. Urassa unpubl.). The prevalence of HIV in Mwanza Region in 2003/04 among 15-49 year old adults was reported to be $7.2 \%$ ( $7.0 \%$ in females, $7.5 \%$ in males) (THIS, 2005).

In 1991, the HIV prevalence among 15-54 year old adults in six communities of rural Mwanza Region, Tanzania was $4.7 \%$ in females and $4.1 \%$ in males (Grosskurth et al., 1995a). These six communities acted as the comparison arm within an STD treatment trial that was conducted between 1991 and 1994. The incidence of HIV was 0.9/100PYO and mortality due to HIV was 0.3/100 PYO (Grosskurth et al., 1995a,b; Todd et al., 1997). If this trend had continued, the HIV prevalence would therefore have been higher in 2001 (10 years later) than in 1991 at the baseline of the trial. A crosssectional study was conducted in 2001 in the same six communities which showed that the prevalence of HIV had not risen as expected (See Table 1).

We hypothesized that this finding could be explained by epidemiological factors such as the effect of HIV mortality, population mobility and changes in determinants of HIV incidence and STD services or weaknesses in the study design such as sample incomparability and random chance.

The objective of this analysis was to determine which of the above factors might have contributed to the relatively stable pattern of the HIV prevalence observed in the comparison arm of the Mwanza STD treatment trial in rural Mwanza Region, Tanzania between 1991 and 2001.

\section{Materials and Methods}

\section{Study area}

The study was conducted in the rural areas of Mwanza Region on the southern shores of Lake Victoria in northwest Tanzania (see Figure 1). Mwanza Region covers an area of 35,872 square $\mathrm{Km}$ and had a population of about 3 million ( $50 \%$ women) in 2002 (URT, 2003).

\section{Data collection}

To evaluate the impact of the introduction of syndromic treatment of STDs onto local government health facilities on HIV incidence, approximately 12,000 adults aged 15-54 years were recruited in 12 communities of rural Mwanza Region (6 intervention, 6 comparison) in 1991 (Grosskurth et al., 1995a; Hayes et al., 1995). Each of these 12 trial communities was divided into
20 clusters and cluster sampling was used to select 7-9 clusters in each community. All eligible adults were asked to attend at a convenient place in the cluster for interviews, clinical examination and for provision of blood sample for HIV testing. Those who did not attend were followed up at their homes and, where possible, recruited. A survey of sexual behaviour was carried out 4-14 months after the baseline survey on a sub-sample of one in eight individuals selected from the cohort by simple random sampling (Munguti et al., 1997). The follow-up survey of this trial was conducted in 1993 (Grosskurth et al., 1995b).

In 2001, we returned to the six comparison arm communities to conduct a cross-sectional study on the association between population mobility and the spread of HIV. Within the six communities, a similar sampling scheme was used to randomly select six clusters. In each selected cluster, 14 neighbouring households were randomly selected and all adults aged 15-54 years from these households were asked to participate in this study. Those who consented to participate were interviewed, examined and asked to provide a finger prick blood specimen. Households were revisited at least twice to look for previously absent household members between 1-7 days later while the teams were still in the community. A follow-up to the 2001 study was conducted in 2004 to investigate the association between HIV incidence and changes of household residence.

In both the 1991 and 2001 survey the methods were similar. Structured questionnaires were used to collect socio-demographic and sexual behaviour data. All respondents who presented with symptoms suggestive of sexually transmitted diseases (STDs) were offered free treatment. Blood was tested for HIV-1 antibodies using two independent enzyme-linked immunosorbent assays - GACELISA (Murex \& Organon, Organon Technical, UK) in 1991 and UNIFORM II (Vironostika) and ENZYGNOST (Dade Behring AG) in 2001. Western Blot and ENZYGNOST tests were used to confirm HIV sero-positivity in the 1991 and in the 2001 survey, respectively. Only blood samples that were reactive to the confirmatory test were defined to be HIV positive.

The study protocols were approved by the Research Ethics Review Committee of the Medical Research Coordinating Committee, Tanzania, and the Ethics Committee of the London School of Hygiene and Tropical Medicine of the United Kingdom.

\section{Data analysis}

HIV sero-prevalence and incidence data from the two surveys were compared using direct standardisation from 
the 2002 Mwanza rural population census (URT, 2003). We also compared data for relevant socio-demographic and sexual behaviour characteristics in 1991 and 2001 including age, religion, occupation, education, age of sexual debut, numbers of lifetime and recent (in past 12 months) sexual partners, condom use at last sexual intercourse, and reporting of STD symptoms in the past year. Approximate Chi square tests for heterogeneity with its associated p-values (0.05 alpha level) were obtained and are presented where appropriate. Statistical analysis was done using STATA version 7 (Stata Corp 2001).

\section{Results}

In these six communities, 7992, and 1710 individuals were eligible for the 1991 and 2001 surveys respectively; of whom 6394 [3399 (53.2\%) in females, 2995 (46.8\%) in males] and 1320 [753 (57.0\%) in females, 567 (43.0\%) in males] were seen and interviewed in the respective surveys. In the 1991/92 sexual behaviour survey, 582 [301 (51.7\%) in females, $281(48.3 \%)$ in males] of 789 eligible respondents were seen and interviewed.
A larger proportion of females than males was interviewed in 2001 than in 1991 (the sex ratio was $0.88: 1$ in the $1991 / 92$ and $0.75: 1$ in the 2001 surveys, respectively). Mean ages of those interviewed were similar (the mean age for the 1991/92 and 2001 surveys were 30.8 years and 29.4 years for males and 29.8 years and 28.2 years for females respectively).

The crude and the age standardised HIV prevalence are presented in Table 1. The age standardised HIV prevalence were not significantly different between 1991 and 2001 sero-surveys $(Z=-0.56, P=0.58$ for males; $\mathrm{Z}=0.64, \mathrm{P}=0.52$ for females). Adjusting for the effect of age on HIV prevalence decreased slightly the HIV prevalence in 1991/92, 1993/94 and 2001 sero-surveys for both sexes except for females in 1993/94.

The age standardised HIV incidence in the 19911993 study was higher than the age standardised HIV incidence in 2001-2004 (standardised rate ratio 1.7; 95\% CI: 1.0 - 2.5) and the age standardised mortality due to HIV was also higher in 1991-1993 than in the 2001-2004 study (standardised rate ratio 1.4; 95\% CI: 1.0-2.0).

Female participants in the 2001 survey were significantly more likely to be Catholics or Protestants, single and educated and significantly less likely to be

Table 1: HIV prevalence data for the Baseline Survey in 1991/92, Sexual Behaviour Study 1991/92, Followup Survey 1993/94 and the Population Mobility Study in 2001

\begin{tabular}{|c|c|c|c|c|c|}
\hline \multirow{2}{*}{ Characteristic } & \multirow[t]{2}{*}{ Sex } & \multicolumn{3}{|c|}{ Comparison Communities in the STD intervention trial } & \multirow{2}{*}{$\begin{array}{c}\text { Population } \\
\text { Mobility study } \\
2001 \text { (n=1710) }\end{array}$} \\
\hline & & $\begin{array}{l}\text { Baseline Survey } \\
1991 / 92(n=6394)\end{array}$ & $\begin{array}{l}\text { Behaviour sur- } \\
\text { vey in 1991/92 } \\
(\mathrm{n}=582)\end{array}$ & $\begin{array}{l}\text { Follow-up Survey } \\
\text { 1993/94 (n=4559) }\end{array}$ & \\
\hline \multirow[t]{2}{*}{ Participation } & Male & $\mathrm{NA}^{\mathrm{a}}$ & $\mathrm{NA}^{\mathrm{b}}$ & $73 \%$ & $71 \%$ \\
\hline & Female & NA & NA & $70 \%$ & $83 \%$ \\
\hline Age range & & $15-54$ & $15-54$ & $15-54$ & $15-54$ \\
\hline \multirow{2}{*}{$\begin{array}{l}\text { HIV prevalence } \\
\text { (crude) }\end{array}$} & Male & $4.1 \%$ (CI: 3.4-4.9) & NA & $4.4 \%$ (CI: $3.6-5.4$ ) & $4.4 \%$ (CI: 3.0-6.6) \\
\hline & Female & $4.7 \%$ (CI: $4.0-5.4)$ & NA & $4.8 \%$ (CI: $3.9-5.7)$ & $4.2 \%(\mathrm{CI}: 2.9-5.9)$ \\
\hline \multirow{2}{*}{$\begin{array}{l}\text { HIV prevalence } \\
\text { (age adjusted) }\end{array}$} & Male & $3.8 \%$ (CI: 3.2-4.6) & NA & $3.8 \%$ (CI: $3.0-4.7)$ & $4.3 \%$ (CI: $2.8-6.4)$ \\
\hline & Female & $4.5 \%$ (CI: $3.8-5.3)$ & NA & $4.8 \%$ (CI: $3.9-5.7)$ & $3.9 \%(\mathrm{CI}: 2.6-5.6)$ \\
\hline \multicolumn{2}{|l|}{$\begin{array}{l}\text { Age standardised } \\
\text { HIV incidence }\end{array}$} & \multicolumn{3}{|c|}{ 1.0/100 (0.5 -1.8) PYOף } & $\begin{array}{l}0.6 / 100(0.2-1.8) \\
\text { PYO§ }\end{array}$ \\
\hline \multicolumn{2}{|l|}{$\begin{array}{l}\text { Age Standardised } \\
\text { Mortality due to } \\
\text { HIV }\end{array}$} & \multicolumn{3}{|l|}{$0.3 / 100(0.2-0.5) \mathrm{PYO}$} & $\begin{array}{l}0.2 / 100(0.1-0.5) \\
\text { PYO }\end{array}$ \\
\hline
\end{tabular}

\footnotetext{
Source: Grosskurth et al. 1995a, Grosskurth et al. 1995b, Munguti et al. 1997. CI are given at 95\%

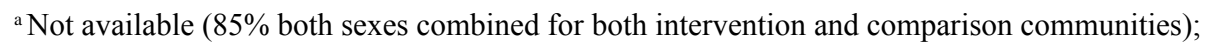

${ }^{\mathrm{b}}$ Not available (75\% Males, $74 \%$ females for both intervention and comparison communities);

ๆ 1991/92-1993/94; § 2001-2004
} 
farmers than female participants in the 1991 behaviour survey. Male participants in 2001 were significantly more likely to be farmers or students than male participants in the behaviour survey. However, there was no significant difference between females in the two surveys in terms of their age pattern or ethnic group. Likewise, there was no significant difference between males in terms of their age pattern, religion, marital status, ethnic group and education (Table 2).

Table 2 Socio-demographic and sexual behaviour characteristics in 1991/92 and 2001 surveys

\begin{tabular}{|c|c|c|c|c|c|c|}
\hline \multirow[b]{2}{*}{ Variable } & \multicolumn{3}{|c|}{ Males } & \multicolumn{3}{|l|}{ Females } \\
\hline & $\begin{array}{l}\text { 1991/92 } \\
n=281(\%)\end{array}$ & $\begin{array}{l}2001 \\
n=567(\%)\end{array}$ & $X^{2}$ (P value) & $\begin{array}{l}1991 / 92 \\
n=301(\%)\end{array}$ & $\begin{array}{l}2001 \\
n=753(\%)\end{array}$ & $X^{2}$ (P value) \\
\hline \multicolumn{7}{|l|}{ Age (years) } \\
\hline $15-24$ & 98 (35) & 213 (38) & \multirow{4}{*}{$5.4(0.14)$} & 115 (38) & 321 (43) & \multirow{4}{*}{$3.6(0.31)$} \\
\hline $25-34$ & 89 (32) & $180(32)$ & & $93(32)$ & $241(32)$ & \\
\hline $35-44$ & 48 (17) & 112 (20) & & 55 (18) & $116(15)$ & \\
\hline $45-54$ & $46(16)$ & $62(11)$ & & $38(13)$ & 75 (10) & \\
\hline \multicolumn{7}{|l|}{ Religion } \\
\hline Moslem & $11(4)$ & $21(4)$ & \multirow{4}{*}{$0.7(0.88)$} & $24(8)$ & $23(3)$ & \multirow{4}{*}{$40.7(<0.001)$} \\
\hline Catholic & $113(40)$ & 217 (38) & & $131(44)$ & $378(50)$ & \\
\hline Protestant & 84 (30) & 185 (33) & & 76 (25) & $266(35)$ & \\
\hline Other & $73(26)$ & $144(25)$ & & 70 (23) & $86(11)$ & \\
\hline \multicolumn{7}{|l|}{ Occupation } \\
\hline Farmer & $228(81)$ & $478(84)$ & \multirow{3}{*}{$31.5(<0.001)$} & 285 (95) & 677 (90) & \multirow{3}{*}{$6.4(0.041)$} \\
\hline Student & $13(5)$ & $63(11)$ & & $8(3)$ & $44(6)$ & \\
\hline Manual/Office/ Business/ Others & $40(14)$ & $26(5)$ & & $8(3)$ & $32(4)$ & \\
\hline \multicolumn{7}{|l|}{ Marital status } \\
\hline Never married & $85(30)$ & $194(34)$ & \multirow{4}{*}{$3.4(0.34)$} & 39 (13) & $174(23)$ & \multirow{4}{*}{$20.6(<0.001)$} \\
\hline Monogamous & $153(54)$ & $284(50)$ & & $179(59)$ & $361(48)$ & \\
\hline Polygamous & $28(10)$ & $47(8)$ & & $54(18)$ & $114(15)$ & \\
\hline Widowed / Separated / Divorced & $15(5)$ & $42(7)$ & & $29(10)$ & $104(14)$ & \\
\hline \multicolumn{7}{|l|}{ Ethnic group } \\
\hline Sukuma & 195 (69) & $423(75)$ & \multirow{3}{*}{$2.6(0.27)$} & $220(73)$ & $532(71)$ & \multirow{3}{*}{$1.8(0.404)$} \\
\hline Kara/Kerewe & 37 (13) & $63(11)$ & & $35(12)$ & $80(11)$ & \\
\hline Others & 49 (17) & $81(14)$ & & $46(15)$ & 141 (19) & \\
\hline \multicolumn{7}{|l|}{ Education } \\
\hline No formal & $40(14)$ & $77(14)$ & \multirow{3}{*}{$0.1(0.93)$} & $125(42)$ & $195(26)$ & \multirow{3}{*}{$27.1(<0.001)$} \\
\hline Primary & $227(81)$ & $464(82)$ & & $174(58)$ & $539(72)$ & \\
\hline Post primary & $14(5)$ & $26(5)$ & & $2(1)$ & $19(3)$ & \\
\hline \multicolumn{7}{|l|}{ Reported lifetime sexual partners ${ }^{\text {a }}$} \\
\hline \multicolumn{7}{|l|}{ None } \\
\hline 1 & $9(3)$ & $60(11)$ & \multirow{4}{*}{$22.8(<0.001)$} & $11(4)$ & 79 (11) & \multirow{4}{*}{$15.3(0.002)$} \\
\hline $2-4$ & $13(5)$ & $36(7)$ & & $75(26)$ & $161(21)$ & \\
\hline $5+$ & $61(22)$ & $149(27)$ & & $152(53)$ & 412 (55) & \\
\hline & $196(70)$ & $306(56)$ & & $50(17)$ & $100(13)$ & \\
\hline $\begin{array}{l}\text { Reported sexual partners in the } \\
\text { months }{ }^{b}\end{array}$ & & & & & & \\
\hline None & $27(10)$ & $90(16)$ & & $29(10)$ & $121(16)$ & \\
\hline 1 & $100(36)$ & $214(38)$ & $9.7(0.022)$ & 247 (83) & $551(73)$ & $11.0(0.012)$ \\
\hline $2-4$ & $69(25)$ & $132(23)$ & & $19(6)$ & $62(8)$ & \\
\hline $5+$ & $85(30)$ & $130(23)$ & & $4(1)$ & $19(3)$ & \\
\hline $\begin{array}{l}\text { Condom use at last sex with } \\
\text { partners in the last year }\end{array}$ & $7(2)$ & $71(13)$ & $22.6(<0.001)$ & $1(1)$ & $46(6)$ & $16.8(<0.001)$ \\
\hline STD syndrome past year & $58(21)$ & $23(4)$ & $59.8(<0.001)$ & $45(15)$ & $35(5)$ & $32.5(<0.001)$ \\
\hline
\end{tabular}

a men and 13 women in the behaviour survey and 16 men and 1 woman in 2001 did not respond

b 2 women in the behaviour survey and 1 man in 2001 survey did not respond

In the 2001 survey, participants of both sexes reported a significantly smaller number of lifetime sexual partners, sexual partners in the last 12 months and STD syndromes in the past year than participants in the behaviour survey in 1991. They also reported significantly more condom use at last sex with casual sexual partners and a later sexual debut (Figure 2) than participants in the behaviour survey in 1991. 


\section{Discussion}

Over a 10 year period (1991 to 2001) in these six communities of rural Mwanza Region the estimates of the age standardised HIV prevalence rose from $3.8 \%$ to $4.3 \%$ in males and declined from $4.5 \%$ to $3.9 \%$ in females. At the beginning of the period, the age standardised HIV incidence was 1/100PYO and the excess mortality due to HIV was $0.3 / 100 \mathrm{PYO}$ (Grosskurth et al., 1995a; Todd et al., 1997). With this incidence and from models of the HIV epidemic, an

\section{a) Males}

Possible explanations include study design issues such as random chance and sample incomparability or epidemiological factors such as the effect of HIV mortality, population mobility, intervention programs or changes in sexual behaviour in the study communities after the trial.

The survey in 1991 obtained the HIV prevalence data from a population of over 6000 people in the study communities (Grosskurth et al., 1995a; Todd et al., 1997), while the survey in 2001 involved 1300 subjects. The age and sex standardised prevalence were $4.2 \%$ (95\%

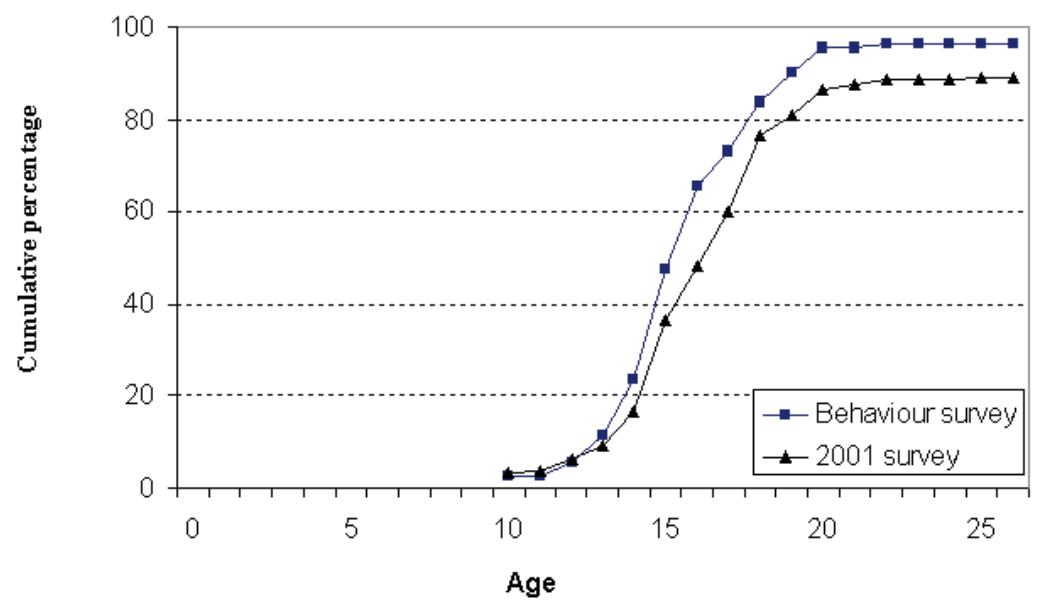

a) Females

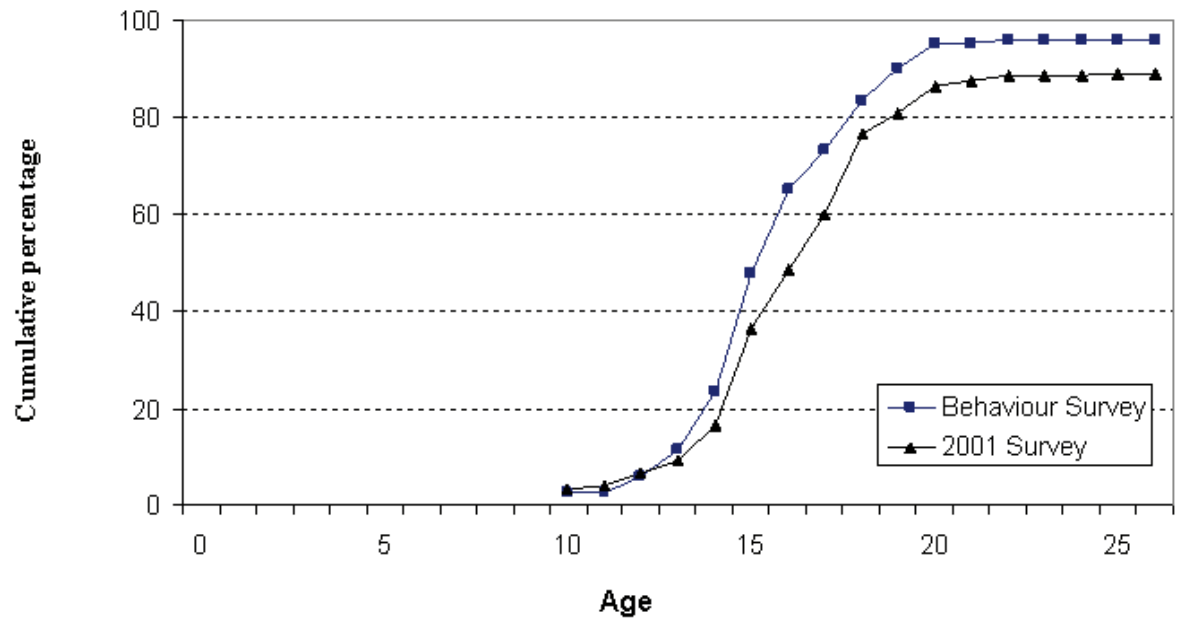

Figure 1: Reported age at sexual debut by sex in the 1991 behaviour and 2001 surveys

HIV prevalence of $8-10 \%$ was expected in these rural communities by 2001 (Korenromp, 2001). It is critical to understand why the HIV prevalence had not increased in the study communities in 2001 as expected. This has an implication on practical HIV prevention policies. Specific questions include: Has HIV infection reached a plateau in Mwanza Region of Tanzania? Are there other alternative explanations for the HIV prevalence remaining the same from 1991 to 2001 ?
CI: $3.7 \%-4.7 \%$ ) in the six comparison communities of the Mwanza HIV/STD trial in 1991, 4.8\% (95\% CI: $4.2 \%-5.5 \%$ ) in the follow-up survey in 1993 and $4.1 \%$ (95\% CI: $3.1 \%-5.3 \%)$ in 2001 ( $\chi^{2}$ for linear trend $=0.4$, $\mathrm{P}=0.53$ ). The 2001 survey was designed to detect a $73 \%$ or more increase in HIV prevalence between 1993 and 2001 (i.e. from $4.8 \%$ in 1993 to $8.3 \%$ in 2001) with $80 \%$ power and $90 \%$ confidence interval. The upper limits of the $95 \%$ confidence interval for the standardised HIV prevalence in 2001 for males and females were both 
considerably less than $8 \%(6.4 \%$ in males, $5.6 \%$ in females). It is therefore unlikely that the HIV prevalence observed in 2001 has been affected by chance alone.

Sample incomparability should not have biased the HIV prevalence of the two surveys because the same communities were used and the cluster-randomised sampling schemes were similar. The field procedures and the laboratory testing schemes were similar and were all carried out within the same laboratory at the National Institute for Medical Research in Mwanza. Age and sex standardisation was done to directly compare the HIV prevalence in the two studies.

The Mwanza STD syndromic management intervention trial observed a rising HIV epidemic with a standardised incidence rate of $1 / 100 \mathrm{PY}$ and an incidence of HIV-associated mortality of 0.3/100PY in the comparison communities among 15-54 year olds in 1991 (Grosskurth et al., 1995b; Todd et al., 1997). It is possible that increased mortality related to HIV would affect the prevalence of HIV by the year 2001 . Simulations models have indicated that mortality rates initially increase slowly followed by a rapid increase 5 to 10 years into the epidemic, and stabilizing around 15 to 20 years after the onset of the epidemic in the general population (Gregson \& Garnett, 1994). It is thought that HIV was introduced in Mwanza Region around 1985 (MoH, 2000, 2005). Incidence of HIV-associated mortality was $0.2 / 100 \mathrm{PY}$ in 2004 which suggests that the excess mortality due to HIV was lower in 2004 compared to 1993.

In the follow up to the 1991 survey, HIV-positive individuals were slightly more likely to have moved or travelled than HIV-negative individuals (25\% vs $21 \%$ females; $23 \%$ vs $18 \%$ males). The lower than expected HIV prevalence in 2001 could be explained if more HIV positive subjects moved out of these rural communities than into the area. This is supported by longitudinal data collected in 2001 and 2004. The 2001 prevalence of HIV was significantly higher in those who were not seen in $2004(6.6 \%$; 95\% CI: 4.2\%-9.9\%) than in those who were seen in 2004 (3.0\%; 95\% CI: $2.0 \%-4.4 \%)(Z=2.87$, $\mathrm{P}=0.004)$. This may suggest that people who are HIV positive are more likely to move out of these rural communities either due to stigma and discrimination, seeking medical care in hospitals/traditional healers, because they came from a more mobile group within the community or for other reasons. However, data were not collected on people who moved into the study area for terminal care. It is likely therefore; that the slightly lower HIV prevalence observed in 2001 can be explained by population dynamics.

The 2001 study shows major changes in reported sexual behaviour since 1991/92 with a decreased reporting of number of sexual partners and higher condom use reported in 2001. During the STD syndromic management intervention trial, there was no significant sexual behaviour change (Grosskurth et al., 1995b). In 1995, a year after the completion of the trial, all communities in Mwanza received STD syndromic management interventions through the Regional Medical Office, with assistance from African Medical Research Foundation (AMREF). In Kisesa ward in Mwanza, Tanzania, in 1996, 39\% of women and $46 \%$ of men who reported genital discharge or ulcer visited a health facility for treatment (Boerma et al., 2002). In 1998, a survey of 4 health facilities in rural Mwanza showed that 122 STD patients were seen over a two week period, and $84(69 \%)$ were given the correct treatment for their STD (Buve et al., 2001). The 2001 survey in Mwanza region showed that $64 \%$ of the health service providers had been trained in syndromic management of STDs by end of 2001 (Oliff, 2002). It is plausible that these HIV interventions may have slowed down the rising pattern of the epidemic observed during the Mwanza STD syndromic management intervention trial.

This similar HIV prevalence in 1991/92 and 2001 is likely to be due to the reduction in risk behaviour and improved STD management following the STD syndromic treatment trial. STD/ HIV prevention activities in rural Mwanza Region and other secular changes in risk behaviour may have successfully impeded the spread of HIV infection. Population dynamics may provide alternative explanation though modelling studies are needed to assess whether mobility of HIV infected people out of rural communities may stabilise the prevalence of the HIV infection in the general populations. Prevention activities should therefore be enhanced to reduce HIV incidence even further.

\section{Acknowledgements}

We thank Dr. Andrew Y. Kitua, Director General, National Institute for Medical Research for permission to publish the manuscript. We are grateful to all our respondents for their valuable time and information. We would also like to thank our dedicated fieldworkers, Cyprian Mussolini, Christina Manyama, Grace Mutolela, Victoria Sitta, Illuminata Machumi, and Frank Gwaluma. We also thank Julius Mngara, Dhamira Ngerageza and Miyaye for laboratory analysis. This study was funded by the Department for International Development (DFID) and the Wellcome Trust.

\section{Received 19 May 2008}

Revised 5 June 2008

Accepted 13 June 2008 


\section{References}

Barongo, L.R., Borgodoff, M.W., Mosha, F.F., Nicoll, A., Grosskurth, H., Senkoro, K.P., Newell, J.N., Changalucha, J., Klokke, A.H. \& Killewo, J.Z. (1992) The epidemiology of HIV-1 infection in urban areas, roadside settlements and rural villages in Mwanza region, Tanzania. AIDS 6, 1521-1528.

Boerma, J.T., Urassa, M., Nnko, S., Ng’weshemi, J., Isingo, R., Zaba, B. \& Mwaluko, G. (2002) Sociodemographic context of the AIDS epidemic in a rural area in Tanzania with a focus on people's mobility and marriage. Sexually Transmitted Infections 78 (Suppl. 1), i97-i105.

Buve, A., Changalucha, J., Mayaud, P., Gavyole, A., Mugeye, K., Todd, J., Clayton, T., Mosha, F., Grosskurth, H., Mabey, D., Laga, M., Van Lerberghe, W. \& Hayes, R.J. (2001) How many patients with a sexually transmitted infection are cured by health services? A study from Mwanza region, Tanzania. Tropical Medicine and International Health 6, 971-979.

Gregson, S. \& Garnett, G.P. (1994) Is HIV-1 likely to become a leading cause of adult mortality in sub-Saharan Africa? Journal of Acquired Immune Deficiency Syndromes 7, 839-852.

Grosskurth, H., Mosha, F., Todd, J., Senkoro, K., Newell, J., Klokke, A., Changalucha, J., West, B., Mayaud, P., Gavyole, A., Gabone, R., Mabey, D. \& Hayes, R. (1995a) A community trial of the impact of improved STD treatment on the HIV epidemic in rural Tanzania:2. Baseline survey results. AIDS 9, 927-934.

Grosskurth, H., Mosha, F., Todd, J., Mwijarubi, E., Klokke, A., Senkoro, K., Mayaud, P., Changalucha, J., Nicoll, A., Ka-Gina, G., Newell, J., Mugeye, K., Mabey, D. \& Hayes, R. (1995b) Impact of improved treatment of sexually transmitted diseases on HIV infection in rural Tanzania: randomised controlled trial. Lancet 346, 530-536.

Hayes, R., Mosha, F., Nicoll, A., Grosskurth, H., Newell, J., Todd, J., Killewo, J., Rugemalila, J. \& Mabey, D. (1995) A community trial of the impact of improved sexually transmitted disease treatment on the HIV epidemic in rural Tanzania: 1. Design. AIDS 9, 919-926.

Korenromp, E.L. (2001) Treatment of Sexually Transmitted Diseases as an HIV Prevention Strategy. PhD Thesis, Erasmus University, Rotterdam.

Kwesigabo, G., Killewo, J., Godoy, C., Urassa, W., Mbena, E., Mhalu, F., Biberfeld, G., Wall, S. \& Sandstrom, A. (1998) Decline in the prevalence of HIV-1 infection in young women in the Kagera region of Tanzania. Journal of Acquired Immune Deficiency Syndromes Human Retrovirology 17, 262-268.

Kwesigabo, G. (2000) Trends of HIV Infection in the Kagera Region of Tanzania 1987-2000 [Medical Dissertation], Umea University.

MoH (2000) HIV/AIDS/STD Surveillance Report No.15. National AIDS Control Programme, Ministry of Health, Dar-es-Salaam, Tanzania.

MoH (2005) HIV/AIDS/STD Surveillance Report No.19. National AIDS Control Programme, Ministry of Health, Dar-es-Salaam, Tanzania.

Munguti, K., Grosskurth, H., Newell, J.N., Senkoro, K., Mosha, F.F., Todd, J,, Mayaud, P., Gavyole, A., Quigley, M. \& Hayes, R. (1997) Patterns of sexual behaviour in a rural population in NorthWestern Tanzania. Social Science and Medicine 44,1553-1561.

Mwaluko, G., Urassa, M., Isingo, R., Zaba, B. \& Boerma, J.T. (2003) Trends in HIV and sexual behaviour in a longitudinal study in a rural population in Tanzania 1994-2000. AIDS 17, 2645-2651.

Oliff, M.S. (2002) Integrated STI Services into Reproductive Health Services in Tanzania: An Operational Analysis of Opportunities, Barriers and Achievements, PhD Thesis, London School of Hygiene and Tropical Medicine, UK.

Senkoro, K., Boerma, J.T., Klokke, A.H., Ng’weshemi, J.Z., Muro, A.S., Gabone, R., Borgdorff, M.W. (2000) HIV incidence and HIV-associated mortality in a cohort of factory workers and their spouses in Tanzania, 1991 through 1996. Journal of Acquired Immune Deficiency Syndromes 23, 194-202.

THIS (2005) Tanzania HIV/AIDS Indicator Survey 2003-04. Calverton, Maryland, USA: National Bureau of Statistics (NBS) and ORC Macro.

Todd, J., Balira, R., Grosskurth, H., Mayaud, P., Mosha, F., ka-Gina, G., Klokke, A., Gabone, R., Gavyole, A., Mabey, D. \& Hayes, R. (1997) HIV-associated adult mortality in a rural Tanzanian population. AIDS 11, 801-807.

UNAIDS (2007) Report on the Global HIV/AIDS Epidemic. Geneva.

UNAIDS (1999) Trends in HIV Incidence and Prevalence: Natural Course of the Epidemic or Results of Behavioural Change? Geneva.

URT (2003) The 2002 Population and Housing Census: General Report. National Bureau of Statistics, Dar-es-Salaam, Tanzania

WHO (2000) AIDS Epidemic Update. World Health Organization, Geneva. 